\title{
DAYA DUKUNG DAN KESESUAIAN LAHAN EKOWISATA MANGROVE TONGKE-TONGKE KABUPATEN SINJAI SULAWESI SELATAN
}

\author{
Wahdaniar1', Jafron Wasiq Hidayat², dan Fuad Muhammad²
}

1Magister Biologi Universitas Diponegoro;email:niarwahdaniar03@gmail.com

2Fakultas Sains Dan Matematika Universitas Diponegoro

\begin{abstract}
ABSTRAK
Perairan pesisir Kabupaten Sinjai memiliki ekosistem wilayah pesisir yang masih relatif baik dengan luas masing-masing yaitu mangrove 720 ha, padang lamun 860 ha, terumbu karang 6.700 ha .Ekosistem mangrove merupakan salah satu ekosistem wilayah pesisir yang mempunyai manfaat ganda yang meliputi: ekologi, ekonomi, sosial budaya dan jasa-jasa lingkungan, sehingga perlu upaya konservasi untuk menyelamatkan sistem rantai kehidupan organisme pesisir, upaya mencapai harus memperhatikan aspek kesesuaian dan daya dukung.Tujuan dari penelitian ini adalah untuk menganalisis kesesuaian dan menghitung daya dukung kawasan ekowisata mangrove.Penelitian dilakukan pada bulan Oktober Desember 2018 dengan pengumpulan data primer melalui observasi lapangan dan data sekunder melalui studi pustaka.Metode yang digunakan yaitu metode deskriptif dengan analisis Indeks Kesesuaian Wisata (IKW) dan Daya Dukung Kawasan (DDK). Hasil perhitungan menunjukkan bahwa kawasan mangrove Tongke-tongke termasuk dalam kategori sangat sesuai (S1) untuk dikembangkan sebagai ekowisata mangrove dengan nilai Indeks Kesesuaian sebesar 87,17 \% dan Daya Dukung Kawasan (DDK) hutan mangrove Tongke-tongke untuk wisata menunjukkan bahwa jumlah maksimal pengunjung yang dapat ditampung pada hutan mangrove Tongke-tongke sebanyak 236 orang, dengan waktu operasional kawasan wisata selama 8 jam kerja per hari.
\end{abstract}

Kata kunci: Ekowisata Mangrove, Indeks Kesesuaian Wisata, Daya Dukung Kawasan Tongke-tongke

\begin{abstract}
The coastal waters of Sinjai Regency have a relatively good coastal area ecosystem with an area of 720 ha, seagrasses 860 ha, coral reefs 6,700 ha. Mangrove ecosystems are one of the coastal ecosystems that have multiple benefits which include: ecology, economics, socio-culture and environmental services, so conservation efforts are needed to save the life chain system of coastal organisms, efforts to achieve must pay attention to suitability and carrying capacity. The purpose of this study was to analyze the suitability and calculate the carrying capacity of the mangrove ecotourism area. The study was conducted in October - December 2018 by collecting primary data through field observations and secondary data through literature. The method used is descriptive method with analysis of Tourism Suitability Index (IKW) and Regional Carrying Capacity (DDK). The calculation results showed that the Tongke-tongke mangrove area was included in the very suitability category (S1) to be developed as mangrove ecotourism with a Suitability Index value of 87,17\% and Regional Carrying Capacity (DDK) Tongke-tongke mangrove forest for tourism showed that the maximum number of visitors can be accommodated in Tongke-tongke mangrove forest as many as 236 people, with operational area of tourist area for 8 working hours per day.
\end{abstract}

Keywords: Mangrove Ecotourism, Tourism Suitability Index, Carrying Capacity of Tongke-tongke Region.

Citation: Wahdaniar, Hidayat, J. W., dan Muhammad, F. (2019). Daya Dukung dan Kesesuaian Lahan Ekowisata Mangrove Tongke-Tongke Kabupaten Sinjai Sulawesi Selatan. Jurnal Ilmu Lingkungan, 17(3),481-485, doi:10.14710/jil.17.3.481-485

\section{Pendahuluan}

Sulawesi Selatan dengan dengan panjang garis pantai mencapai $1.937 \mathrm{~km}$ dan jumlah pulau 299 buah, merupakan habitat yang potensial bagi tumbuh dan berkembangnya ekosistem mangrove.Kabupaten Sinjai merupakan salah satu daerah yang berada di Sulawesi Selatan yang mempunyai kawasan mangrove paling luas sekitar 173,5 Hektar (Akbar A.S, 2014).
Perairan pesisir Kabupaten Sinjai memiliki ekosistem wilayah pesisir yang masih relatif baik dengan luas masing-masing yaitu mangrove 720 ha, padang lamun 860 ha, terumbu karang 6.700 ha dan terdapat beberapa estuaria yang dihuni berbagai spesies ikan, udang dan kerang-kerang(Malik A, 2015).

Ekosistem mangrove merupakan salah satu ekosistem wilayah pesisir yang mempunyai manfaat 
ganda yang meliputi: ekologi, ekonomi, sosial budaya dan jasa-jasa lingkungan, sehingga perlu upaya konservasi untuk menyelamatkan sistem rantai kehidupan organisme pesisir. Upaya penyelamatan ekosistem hutan mangrove di Kabupaten Sinjai dimulai sejak tahun 1986 dengan swadaya masyarakat dan kerjasama pemerintah dengan adanya Peraturan Daerah No. 8 Tahun 1999, dan hingga tahun 2005 telah berhasil menanam mangrove seluas 720 ha yang tersebar pada beberapa desa di pesisir(Sobari, M.P.,L.Adrianto, 2016).

Ekosistem mangrove di Desa Tongke-tongke merupakan salah satu hutan mangrove yang terbaik di Sulawesi Selatan.Mangrove di Tongke-tongke merupakan perpaduan antara mangrove alami dan hasil rehabilitasi.Rehabilitasi hutan mangrove di Desa Tongke-tongke telah dilakukan sejak tahun 1986 oleh masyarakat desa tersebut secara swadaya. Upaya penghijauan kembali wilayah pesisir ini dilakukan oleh Kelompok Pencinta Sumber Daya Alam - Aku Cinta Indonesia (KPSDA-ACI) dan sudah terlihat tingkat keberhasilannya, dilihat dengan semakin bertambahnya jenis mangrove yang hidup dan luasnya area yang ditumbuhi mangrove sehingga sekarang dijadikan sebagai ekowisata hutan mangrove(Ernawati, Niartiningsih, Nessa, \& Omar, 2002)

Keberadaan ekosistem mangrove di Kabupaten Sinjai belakangan ini sudah mulai dirasakan manfaatnya oleh masyarakat pesisir baik secara langsung maupun secara tidak langsung.Oleh karena itu, perlu upaya dalam pengelolaan agar fungsi dapat berkelanjutan, sehingga mempengaruhi peningkatan kesejahteraan masyarakat petani tambak dan nelayan, serta masyarakat lainnya sebagai penyedia jasa sarana produksi (saprodi) untuk kebutuhan petani tambak dan nelayan. Ekowisata hutan mangrove mengkaji tentang eksplorasi potensi wisata untuk konservasi dan pembangunan serta mencegah dampak negatif terhadap ekosistem, kebudayaan, dan keindahan. Namun demikian, pemanfaatan sumberdaya ekosistem mangrove untuk ekowisata harus disertai pertimbangan yang cermat khususnya mengenai daya dukung kawasan. Pengembangan wisata yang hanya mengejar keuntungan semata justru akan berdampak negatif, baik pada sisi ekologis, sosial maupun ekonominya. Hal ini terjadi pada beberapa kawasan wisata pantai dan pesisir di dunia ini yang di fokuskan pada pencapainya tujuan jangka pendek, yang mengakibatkan hancurnya parawisata.itu sendiri. Kasus-kasus ini pula yang mendorong munculnya konsep pengembangan ekowisata.

Undang-undang Nomor 32 Tahun 2009 tentang Perlindungan dan Pengelolaan Lingkungan Hidup Pasal 1 angka 7 di sebutkan bahwa daya dukung lingkungan hidup adalah kemampuan lingkungan hidup untuk mendukung perkehidupan manusia, mahluk hidup lain, dan keseimbangan antar keduanya. Daya tampung lingkungan hidup adalah kemampuan lingkungan hidup untuk menyerap zat ,energy, dan/atau komponen lain yang masuk atau di masukkan ke dalamnya. Peraturan Menteri Negara Lingkungan Hidup Nomor 17 tahun 2009 Tentang pedoman Penentuan Daya Dukung Lingkungan Hidup dalam penataan Ruang Wilayah menyebutkan bahwa penentuan daya dukung lingkungan hidup dilakukan dengan cara mengetahui kapasitas lingkungan alam dan sumber daya untuk mendukung kegiatan manusia/penduduk yang menggunakan ruang bagi kelangsungan hidup. Besarnya kapasitas tersebut di suatu tempat dipengaruhi oleh keadaan dan karkteristik sumber daya yang ada di hamparan ruang yang bersangkutan. Kapasitas lingkungan hidup sumber daya akan menjadi faktor pembatas dalam penentuan pemanfaatan ruang yang sesuai(Eko Setyawan, 2015).

Penentuan daya dukung lingkungan maupun daya dukung wisata alam bertujuan untuk membatasi penggunaan suatu ruang atau wilayah. Namun keduanya memiliki perbedaan dalam penerapannya.Daya dukung fisik (Physical Carrying Capacity) PCC) merupakan jumlah maksimum wisatawan yang secara fisik tercukupi oleh ruang yang disediakan pada waktu tertentu. Untuk menghitung daya dukung ekologis, daya dukung ekologi merupakan jumlah wisatawan yang dapat melakukan kegiatan dalam kunjungan wisata tanpa menyebabkan kerusakan bagi lingkungan alam, di mana obyek tetap lestari pada tingkat managemen(Siswantoro, 2012).

Pengembangan berbasis sumber daya hayati Tongke-tongke memiliki beranekaragam biota yang hidup disekitaran mangrove akan tetapi rentan terhadap kerusakan apabila kurang bijaksana dalam pengelolaanya dan berkembangnya kawasan pesisir tongke-tongke dan di iringi jumlah penduduk yang bertambah pesat, sehingga berbagai kegiatan yang bertujuan mengembangkan potensi ekonomi dan juga di jadikan sebagai tempat rekreasi (wisata) oleh masyarakat sekitar maupun masyarakat dari luar kabupaten Sinjai, sehingga ekosistem mangrove dan biota di sekitarnya terancam mengalami kerusakan(Hasrayanti., 2017).

Oleh sebab itu, perlu adanya penelitian mengenai kesesuaian dan daya dukung kawasan untuk dijadikan sebagai tempat wisata.Penelitian ini diharapkan dapat menjadi alternatif pendukung dalam pengembangan ekowisata mangrove Tongketongke.

\section{Metode Penelitian}

Penelitian dilakukan dikawasan hutan mangrove Tngke-tongke Kabupaten Sinjai Sulawesi Selatan yang sedang dikembangkan sebagai salah satu tujuan wisata.Penelitian dilaksanakan pada bulan Oktober-Desember 2018.Data yang digunakan dalam analisis adalah data primer dan data sekunder.Data primer berupa data jenis vegetasi, 
kerapatan mangrove dan data biota, sedangkan data sekunder terdiri dari luasan mangrove dan panjang hutan mangrove.

Menurut (Yulianda, 2007) kesesuaian wisata pantai kategori wisata mangrove mempertimbangkan parameter ketebalan, kerapatan, jenis mangrove, pasang surut dan obyek biota dengan klasifikasi penilaian pada Tabel 1.

Tabel 1. Matrik kesesuaian untuk wisata pantai kategori wisata mangrove

\begin{tabular}{|c|c|c|c|c|c|c|c|c|c|c|}
\hline No & Parameter & Bobot & $\begin{array}{c}\text { Kategori } \\
\text { S1 } \\
\end{array}$ & Skor & $\begin{array}{l}\text { Kategori } \\
\text { S2 } \\
\end{array}$ & Skor & $\begin{array}{c}\text { Kategori } \\
\text { S3 } \\
\end{array}$ & Skor & $\begin{array}{c}\text { Kategori } \\
\mathbf{N} \\
\end{array}$ & Skor \\
\hline 1 & $\begin{array}{l}\text { Ketebalan } \\
\text { mangrove }(\mathrm{m})\end{array}$ & 5 & $>500$ & 3 & $>200-500$ & 2 & $50-200$ & 1 & $<50$ & 0 \\
\hline 2 & $\begin{array}{l}\text { Kerapatan } \\
\text { Mangrove }\end{array}$ & 3 & $>15-25$ & 3 & $>10-15$ & 2 & $5-10$ & 1 & $<5$ & 0 \\
\hline 3 & Jenis Mangrove & 3 & $>5$ & 3 & $3-5$ & 2 & $1-2$ & 1 & 0 & 0 \\
\hline 4 & $\begin{array}{l}\text { Pasang Surut } \\
(\mathrm{m})\end{array}$ & 1 & $0-1$ & 3 & $>1-2$ & 2 & $>2-5$ & 1 & $>5$ & 0 \\
\hline 5 & Obyek biota & 1 & $\begin{array}{l}\text { Ikan } \\
\text { Udang } \\
\text { Kepiting } \\
\text { Moluska } \\
\text { Reptil } \\
\text { Burung } \\
\end{array}$ & 3 & $\begin{array}{l}\text { Ikan } \\
\text { Udang } \\
\text { Kepiting } \\
\text { moluska }\end{array}$ & 2 & $\begin{array}{l}\text { Ikan } \\
\text { moluska }\end{array}$ & 1 & $\begin{array}{l}\text { Salah } \\
\text { Satu biota } \\
\text { air }\end{array}$ & 0 \\
\hline
\end{tabular}

Rumus untuk menghitung indeks kesesuaian wisata yaitu

\section{$I K W=\sum(\mathrm{Ni} / \mathrm{Maks}) \times 100 \%$}

Dimana :

IKW : Indeks Kesesuaian Wisata

$\mathrm{Ni} \quad$ : Nilai parameter ke-I (Bobot x skor)

Nmaks :Nilai maksimum dari suatu kategori wisata

Kriteria kesesuaian untuk kawasan wisata mangrove dikategorikan sebagai berikut:

Nilai maksimim $=39$

S1 : Sangat sesuai, dengan nilai $83-100 \%$

S2 : Sesuai, dengan nilai 50- $<83 \%$

S3 : Sesuai bersyarat, dengan nilai $17-, 50$

$\mathrm{N} \quad$ : Tidak sesuai, dengan nilai $<17 \%$

Teknik yang digunakan untuk survei tumbuhan mangrove adalah Kerapatan.Data yang diambil berupa tumbuhan mangrove pada tingkat pohon dengan ukuran diameter $\geq 10 \mathrm{~cm}$. Parameter yang diukur berupa nama jenis tumbuhan mangrove dan jumlah individu setiap jenis yang terdapat pada petak contoh.

Pengamatan Fauna Data yang diambil berupa nama jenis fauna yang ditemukan pada petak contoh. Perhitungan individu pada jenis fauna kepiting, kelomang, dan ikan gelodok menggunakan sampling dengan petak contoh berukuran $25 \mathrm{~cm} \times 25$ $\mathrm{cm}$ pada setiap plot pengamatan (Mchenga 2013) sedangkan jenis fauna lainnya menggunakan teknik wawancara kepada pengelola hutan mangrove yaitu kepala Pokmasi (Kelompok masyarakat konservasi).

DDK (Daya Dukung Kawasan) adalah jumlah maksimum pengunjung yang secara fisik dapat ditampung di kawasan yang disediakan pada waktu tertentu tanpa menimbulkan gangguan pada alam dan manusia. Perhitungan DDK menggunakan rumus berikut(Yulianda, 2007):

$$
D D K=k \times \frac{2 p}{L i} \times \frac{W t}{W_{p}}
$$

Keterangan:

DDK :Daya Dukung Kawasan (orang/hari)

$\mathrm{K} \quad$ :Potensi ekologis pengunjung per satuan unit area (orang)

Lp : Luas/panjang area yang dapat dimanfaatkan $\left(\mathrm{m}^{2}\right.$ atau $\left.\mathrm{m}\right)$

Lt : Unit area untuk kategori tertentu $\left(\mathrm{m}^{2}\right.$ atau $\left.\mathrm{m}\right)$

Wt : Waktu yang disediakan oleh kawasan untuk

kegiatan wisata dalam satu hari (jam)

Wp : Waktu yang dihabiskan oleh pengunjung untuk setiap kegiatan tertentu (jam)

Potensi ekologis pengunjung ditentukan oleh kondisi sumberdaya dan jenis kegiatan yang dikembangkan.Luasan area yang dimanfaatkan pengunjung harus memperhatikan kemampuan alam untuk mentolerir aktivitas pengunjung sehingga keaslian tetap terjaga (Tabel 2.). Waktu kegiatan pengunjung (Wp) dihitung berdasarkan lamanya waktu yang dihabiskan pengunjung untuk berwisata. Waktu pengunjung diperhitungkan dengan waktu yang disediakan kawasan (Wt) yaitu lama waktu areal dibuka dalam satu hari untuk kegiatan wisata (Tabel 2.)

\section{Hasil Dan Pembahasan}

\subsection{Analisis Kesesuaian Mangrove Tongke-tongke} Sinjai

Menurut(Yulianda, 2007)kesesuaian wisata pantai kategori wisata mangrove mempertimbangkan parameter ketebalan, kerapatan, jenis mangrove, pasang surut dan obyek biota. Berdasarkan hasil pengamatan di lapangan, terdapat 8 famili mangrove yang ditemukan di hutan mangrove Tongke-tongke.Rhizophora salah satu jenis yang paling banyak ditemukan.

Mangrove yang ditemukan di Kabupaten sinjai didominasi oleh jenis bakau (Rhizopora sp) dan Api-api (Avicennia sp). 
Tabel 2. Potensi ekologis pengunjung (K), luas area kegiatan (Lt), waktu kunjungan (Wp) dan waktu yang disediakan obyek wisata (Wt)

\begin{tabular}{|c|c|c|c|c|}
\hline No & Jenis Kegiatan & 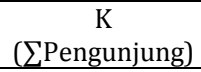 & $\begin{array}{c}\text { Unit Area } \\
\text { (Lt) }\end{array}$ & Keterangan \\
\hline 1 & Selam & 2 & $2000 \mathrm{~m}^{2}$ & Setiap 2 orang dalam $200 \mathrm{~m} \times 10 \mathrm{~m}$ \\
\hline 2 & Snorkeling & 1 & $500 \mathrm{~m}^{2}$ & Setiap 1 orang dalam $100 \mathrm{~m} \times 5 \mathrm{~m}$ \\
\hline 3 & Wisata lamun & 1 & $250 \mathrm{~m}^{2}$ & Setiap 1 orang dalam $50 \mathrm{~m} \times 50 \mathrm{~m}$ \\
\hline 4 & Wisata mangrove & 1 & $50 \mathrm{~m}$ & $\begin{array}{l}\text { Panjang track, setiap } 1 \text { orang sepanjang } 50 \\
\mathrm{~m}\end{array}$ \\
\hline 5 & Rekreasi pantai & 1 & $50 \mathrm{~m}$ & 1 orang setiap $50 \mathrm{~m}$ panjang pantai \\
\hline 6 & Wisata Olaraga & 1 & $50 \mathrm{~m}$ & 1 orang setiap $50 \mathrm{~m}$ panjang pantai \\
\hline
\end{tabular}

Tabel 3. Jenis-jenis tumbuhan mangrove Tongke-tongke Kabupaten Sinjai

\begin{tabular}{cll}
\hline NO & \multicolumn{1}{c}{ Spesies Mangrove } & Nama Daerah \\
\hline 1 & Aegiceras corniculatum & Otti-otti \\
2 & Avicennia alba & Api-api \\
3 & Avicennia officinalis & Api-api \\
4 & Avicennia cylindrica & Api-api \\
5 & Bruguiera cylindrica & Bakko Panda \\
6 & Bruguiera gymnorrhiza & Bakko Panda \\
7 & Ceriop sp & Cokke \\
8 & Nypa Fructicans & Nipa \\
9 & Rhyzophora mucronata & Bakko/Bakau \\
10 & Rhyzophora apiculate & Bakko/Bakau \\
11 & Sonneratia alba & Padada \\
12 & Sonneratia caseolaris & Padada \\
13 & Hibiscus tiliaceus & Haru \\
14 & Pandanus tectorius & Pandan \\
15 & Terminalia catappa & Ketapang \\
\hline
\end{tabular}

\subsection{Kesesuaian Ekologis untuk Kegiatan \\ Ekowisata Mangrove}

Kegiatan wisata yang dikembangkan perlu disesuaikan dengan kondisi sumber daya alam dan peruntukannya. Indeks kesesuaian wisata digunakan sebagai suatu cara untuk mengidentifikasi suatu ekosistem dapat dijadikan sebagai tempat wisata.
Berdasarkan analisis kesesuaian ekologis di hutan mangrove Tongke-tongke memiliki nilai kesesuaian wisata dengan kategori sesuai bersyarat (Tabel 4).Kategori ini menunjukkan bahwa perlu adanya tindakan pengelolaan lebih lanjut dan intensif untuk menjadikan hutan mangrove Tongke-tongke sebagai tempat wisata alam.

Tabel 4. Matrik kesesuaian untuk wisata pantai kategori wisata mangrove

\begin{tabular}{clcccc}
\hline NO & \multicolumn{1}{c}{ Parameter } & Bobot & Skor & Kategori & Nilai \\
\hline 1 & Ketebalan Mangrove & 5 & 2 & S3 & 10 \\
2 & Kerapatan Mangrove & 3 & 3 & S 1 & 9 \\
3 & Jenis Mangrove & 3 & 3 & S1 & 9 \\
4 & Pasang Surut & 1 & 3 & S1 & 3 \\
5 & Obyek Biota & 1 & 3 & S1 & 3 \\
\hline \multicolumn{2}{r}{ Jumlah } \\
\hline
\end{tabular}

Berdasarkan hasil perhitungan kesesuaian wisata kawasan mangrove Tongke-tongke termasuk dalam kategori sangat sesuai (S1) untuk dikembangkan sebagai wisata mangrove dengan nilai Indeks Kesesuaian sebesar 87,17\%. Secara keseluruhan hutan mangrove masuk criteria sangat sesuai (S1) untuk pengembangan wisata jika mengacu kepada parameter kerapatan, jumlah jenis, pasang surut dan keragaman biota.

\subsection{Daya Dukung untuk Kegiatan Wisata}

Daya dukung kawasan merupakan jumlah maksimum pengunjung yang secara fisik dapat ditampung di kawasan yang disediakan pada waktu tertentu tanpa menimbulkan gangguan alam dan manusia. Pemanfaatan kawasan untuk wisata perlu memperhatikan daya dukungnya agar tetap berkelanjutan. Aktivitas yang dapat dilakukan di hutan mangrove Tongke-tongke yaitu tracking, memancing (fishing), piknik, camping, bird watching, edukasi dan photography. Hasil perhitungan daya dukung kawasan hutan mangrove Ciletuh terdapat pada Tabel 5.

Tabel 5. Daya dukung harian kawasan wisata mangrove Tongke-tongke

\begin{tabular}{lcccccc}
\hline Jenis Kegiatan & K & Lp & Lt & Wt (jam) & Wp (Jam) & DDK(Orang/hari) \\
\hline Tracking & 1 & $400 \mathrm{~m}$ & $50 \mathrm{~m}$ & 8 & 2 & 32 \\
Memancing & 1 & $100 \mathrm{~m}$ & $10 \mathrm{~m}$ & 8 & 4 & 20 \\
Rekreasi Pantai & 1 & $300 \mathrm{~m}^{2}$ & $30 \mathrm{~m}^{2}$ & 8 & 2 & 144 \\
Wisata Olaraga & 1 & $500 \mathrm{~m}$ & $50 \mathrm{~m}$ & 8 & 2 & 40 \\
\hline \multicolumn{7}{c}{ TOTAL } \\
\hline
\end{tabular}


Berdasarkan hasil perhitungan tersebut, hutan mangrove Tongke-tongke dapat menampung pengunjung sebanyak 236 orang/hari.Hal ini menunjukkan bahwa jumlah maksimal pengunjung yang dapat ditampung pada hutan mangrove Tongketongke sebanyak 236 orang, dengan waktu operasional kawasan wisata selama 8 jam kerja per hari.

\section{Kesimpulan}

Kawasan mangrove Tongke-tongke termasuk dalam kategorikan sangat sesuai (S1) untuk dikembangkan sebagai wisata mangrove dengan nilai Indeks Kesesuaian sebesar 87,17 \%. Beberapa hal yang mendukung untuk pengembangan wisata bertema konservasi adalah keanekaragaman jenis dan keunikan hutan mangrove serta keragaman biota yang cukup tinggi.Selain itu juga adanya cerita tentangusaha rehabilitasi mangrove hingga berhasil memiliki kerapatan dan ketebalan seperti sekarang ini.Hasil perhitungan menggunakan rumus daya dukung menurut Yulianda (2007), Daya Dukung Kawasan (DDK) hutan mangrove Tongketongkeuntuk wisata menunjukkan bahwa jumlah maksimal pengunjung yang dapat ditampung pada hutan mangrove Tongke-tongke sebanyak 236 orang, dengan waktu operasional kawasan wisata selama 8 jam kerja per hari.

\section{DAFTAR PUSTAKA}

Akbar A.S, M. (2014). Geospatial Modeling of Vegetation Cover Changes on A Small Island - Case Study: Tanakeke Island, Takalar District, South Sulawesi.
Graduate School Bogor Agricultural University.

Eko Setyawan, F. M. dan B. Y. (2015). Kesesuaiam dan Daya Dukung Kawasan untuk Ekowisata Mangrove di Desa Pasarbanggi Kabupaten Rembang Jawa Tengah. Garuda Risekdikti.

Ernawati, S., Niartiningsih, A., Nessa, M. N., \& Omar, S. B. A. (2002). Suksesi Makrozoobentos di Hutan Mangrove Alami dan Rehabilitasi di Kabupaten Sinjai Sulawesi Selatan, Volume 14,(1), .49-60 dimen).

Hasrayanti. (2017). Strategi Komunikasi Dinas Pariwisata dan Kebudayaan Kabupaten Sinjai dalam Pengembangan Hutan Bakau di Desa Tongke-tongke Kecamatan Sinjai Timur. Jurnal Ilmiah.

Malik A. (2015). Strategi Pengembangan Wisata Bahari di Kepulauan Pulau-Pulau Sembilan Kabupaten Sinjai. Universitas Hasanuddin.

Siswantoro, H. (2012). Kajian Daya Dukung Lingkungan Wisata Alam Taman Wisata Alam Curung Sewu Kabupaten Karanganyar. Jurnal Ilmiah.

Sobari, M.P.,L.Adrianto, N. A. (2016). Analisis Ekonomi Aternatif Pengelolaan Ekosistem Mangrove Kecamatan Barru Kabupaten Barru. Buletin Ekonomi Perikanan, 6(3), 1-22.

Pemerintah Republik Indonesia. Undang-Undang Perlindungan dan Pengelolaan Lingkungan Hidup Nomor 32 Tahun 2009.

Peraturan Menteri Negara Lingkungan Hidup Nomor 17 tahun 2009 Tentang Pedoman Penentuan Daya Dukung Lingkungan Hidup dalam Penataan Ruang Wilayah.

Peraturan DaerahKabupaten Sinjai Nomor 8 Tahun 1999 Tentang Kawasan Hutan Lindung.

Yulianda, F. (2007). Ekowisata Bahari Sebagai Alternatif Pemanfaatan Sumberdaya Pesisir Berbasis Konservasi. BOGOR: Departemen Manajemen Sumberdaya Perairan - FPIK. IPB. Bogor. 